\title{
AVALIAÇÃo DA EFICIÊNCIA DE UMA CÉLULA A COMBUSTÍVEL ESTACIONÁRIA DE ÁCIDO FOSFÓRICO
}

Rafael H. Camparin, Luiz A. C. Meleiro e Regina M. M. Jorge

Departamento de Engenharia Química, Universidade Federal do Paraná, CP 19011, 81531-990 Curitiba - PR, Brasil

Mauricio P. Cantão* e Patricio R. Impinnisi

LACTEC - Instituto de Tecnologia para o Desenvolvimento, BR 116, km 98, 81530-980 Curitiba - PR, Brasil

Recebido em 10/5/06; aceito em 9/2/07; publicado na web em 30/7/07

\begin{abstract}
EFFICIENCY EVALUATION FOR STATIONARY PHOSPHORIC ACID FUEL CELL. Operation and performance of a commercial PAFC power plant were analyzed. Processes influencing energy conversion efficiency were studied in each module of the fuel cell power plant. The main processes were simulated using mass and energy balance equations, and the results were validated by means of experimental data. It was concluded that the electrical efficiency is higher in comparison with microturbines. The main result achieved is a better understanding of balance of plant processes, knowledge necessary for fuel cell power plant development.
\end{abstract}

Keywords: fuel cell; balance of plant; efficiency.

\section{INTRODUÇÃO}

Células a combustível são alternativa interessante e promissora na solução dos problemas ambientais provocados pela geração de energia elétrica a partir de combustíveis fósseis. A vantagem da utilização das células a combustível, quando comparadas aos sistemas termoelétricos convencionais, consiste na sua elevada eficiência. O fato de um processo ser mais eficiente que outro significa que para uma mesma quantidade de energia elétrica gerada o consumo de combustível é menor. Com isso, a quantidade de poluentes que são lançados para o meio ambiente, como $\mathrm{CO}_{2}, \mathrm{CO}, \mathrm{NO}_{x}, \mathrm{SO}_{x}$, hidrocarbonetos e particulados, pode ser reduzida ${ }^{1}$.

Células a combustível são dispositivos eletroquímicos que convertem a energia química de um combustível (normalmente o hidrogênio) em eletricidade ${ }^{1-4}$. As células são classificadas segundo o eletrólito utilizado, sendo as principais tecnologias descritas a seguir: - célula de eletrólito polimérico, ou com membrana de troca protônica (PEMFC): opera em temperaturas baixas (em torno de $80^{\circ} \mathrm{C}$ ) e por isso utiliza catalisadores de platina. É adequada à utilização estacionária de pequena potência e à aplicação veicular; célula alcalina (AFC): o eletrólito é uma solução de KOH e conduz íons $\mathrm{OH}^{-}$. Foi bastante utilizada no programa espacial americano, mas sua sensibilidade a $\mathrm{CO}_{2}$ previne sua utilização em sistemas terrestres. A célula alcalina opera em temperaturas próximas de $100{ }^{\circ} \mathrm{C}$;

- célula de ácido fosfórico (PAFC): o ácido fosfórico é condutor protônico a temperaturas entre 150 e $200{ }^{\circ} \mathrm{C}$. O catalisador de platina é menos sensível à contaminação por $\mathrm{CO}$ nesta faixa de temperatura e por isso a célula PAFC apresenta comprovada durabilidade e é bastante adequada à geração estacionária de energia;

- célula de carbonato fundido (MCFC): o eletrólito conduz íons $\mathrm{CO}_{3}{ }^{2-}$ em temperaturas em torno de $700{ }^{\circ} \mathrm{C}$, o que a torna adequada à cogeração e à geração estacionária. A célula MCFC pode, em princípio, ser alimentada diretamente com hidrocarbonetos, convertidos a hidrogênio pelo processo de reforma interna;

- célula de óxido sólido (SOFC): funciona em temperaturas entre 800 e $1000{ }^{\circ} \mathrm{C}$ e pode ser alimentada com hidrogênio e monóxido de carbono. A alta temperatura de operação dificulta a construção e encarece a tecnologia, razão pela qual se buscam cerâmicas

*e-mail: cantao@lactec.org.br condutoras iônicas a temperaturas mais moderadas;

- células de metanol direto e de etanol direto (DMFC e DEFC): são semelhantes às PEMFC, porém com catalisadores capazes de oxidar as moléculas dos álcoois. Células DMFC estão em fase de teste, mas células DEFC, embora interessantes pois o etanol não é tóxico e é renovável, necessitam de soluções tecnológicas. Estas células deverão ser muito utilizadas no mercado de equipamentos portáteis.

O presente estudo baseia-se em uma planta com tecnologia de ácido fosfórico, fabricada pala UTC Fuel Cells, empresa americana de Connecticut. A planta modelo PC25C, mostrada na Figura 1, é alimentada com gás natural reformado a hidrogênio em um reator integrado e gera $200 \mathrm{~kW}$ de potência elétrica e até $260 \mathrm{~kW}$ de energia térmica. A planta foi instalada no LACTEC no modo "turnkey" (pronta para operação) em agosto de 2002 e opera desde então sem grandes problemas. Em mais de $20.000 \mathrm{~h}$ de operação a planta registrou 8 falhas graves, definidas como as quedas de energia com necessidade de intervenção do operador. As falhas tiveram as seguintes causas ${ }^{5}$ : falha mecânica nas válvulas de entrada de ar e de gás natural (3 vezes); sobre-aquecimento de reformador; vazamento de líquido de arrefecimento; falha do ejetor de vapor (o ejetor prepara a mistura de vapor e gás natural que alimenta o reformador); falha do motor da bomba de água do circuito de refrigeração e falha do inversor eletrônico (que converte tensão CC variável em CA constante).

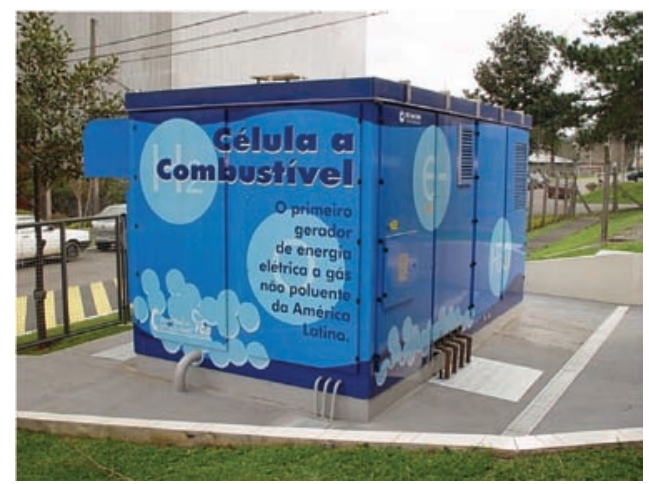

Figura 1. Planta de células a combustível de ácido fosfórico, instalada no LACTEC 
O grande desafio para a utilização em larga escala desta planta é o alto preço, entre US\$ 4,000 a 5,000 por $\mathrm{kW}$ elétrico instalado. Apesar de terem sido fabricadas mais de 400 unidades desta planta, o preço manteve-se constante nos quase 15 anos de produção, criando a visão de que a tecnologia PAFC não tem futuro comercial. No entanto, a operação e manutenção destas unidades nas condições brasileiras mostram que o custo pode ser reduzido, uma vez que os custos da mão-de-obra e dos componentes nacionais (válvulas, motores, atuadores, sensores e tubulação, entre outros) são menores que nos países mais desenvolvidos 5 .

A avaliação econômica da utilização destas plantas em condomínios residenciais, substituindo a eletricidade da rede e deslocando o gás liquefeito de petróleo usado no aquecimento, indica que o preço competitivo das células é de US\$ 3,600 por $\mathrm{kW}$, considerando uma durabilidade de 7 anos para o módulo de conversão eletroquímica ${ }^{5}$. Uma estimativa conservadora de nacionalização mostra que pelo menos $30 \%$ das peças podem ser substituídas por similares nacionais. Neste caso, o custo da planta cairia de US\$ 4,600 para 3,500 por $\mathrm{kW}$, mostrando que a tecnologia PAFC tem potencial de competitividade nos nichos de mercado caracterizados pela eletricidade com tarifa residencial e uso de energético adicional para aquecimento em temperaturas baixas (aplicação residencial, comércio de pequeno porte, alguns hotéis e hospitais).

O preço das microturbinas, em torno de US\$ 1,500 por $\mathrm{kW}$, é consideravelmente menor que o das células a combustível PAFC. Apesar da diferença entre as tecnologias, os custos de operação devem ser semelhantes, o que levaria à conclusão de que o custo da energia seria bem menor para as microturbinas. Entretanto, é necessário levar em conta outros dados, como a durabilidade dos equipamentos e o risco de falha grave com interrupção de fornecimento da energia. A comparação da viabilidade econômica para cada tecnologia não foi feita neste trabalho.

Os resultados aqui apresentados são importantes para a tecnologia nacional de células a combustível. A tecnologia PAFC não consta dos planos de desenvolvimento do MCT, descrito no "Programa de Ciência, Tecnologia e Inovação para a Economia do Hidrogênio" (ProH2) $)^{6}$ e nem é listada no "Roteiro para Estruturação da Economia do Hidrogênio no Brasil"', desenvolvido sob a coordenação do MME. Entretanto, os resultados da pesquisa em células PAFC realizada no Brasil ${ }^{5,8,9}$ e no mundo ${ }^{10-18}$ sugerem uma oportunidade tecnológica ao país. As células PAFC são duráveis, eficientes e podem ser fabricadas com custos competitivos. São menos sensíveis à contaminação por $\mathrm{CO}$ e, portanto, podem ser integradas a reformadores sem a necessidade de purificação do gás combustível em nível de ppm. Esta característica é particularmente importante para os sistemas de reforma de etanol, atualmente em desenvolvimento no Brasil ${ }^{19-22}$.

Neste trabalho são apresentados os resultados da avaliação das eficiências elétrica, térmica e total da célula a combustível estacionária de ácido fosfórico para várias potências elétricas nominais de operação. A avaliação foi feita por modelagem matemática e validada pela comparação dos resultados calculados com parâmetros experimentais. Foi determinada a faixa de operação da planta capaz de garantir eficiências elétricas superiores às apresentadas pela microturbina a gás (Capstone 330 de Alta Pressão ${ }^{23}$ ), adotada como referência por ser a tecnologia termoelétrica mais próxima das células a combustível na faixa até $200 \mathrm{~kW}$.

A energia térmica recuperável é proveniente da exaustão dos gases de combustão da microturbina, cuja temperatura varia entre 200 e $300{ }^{\circ} \mathrm{C}$. O calor produzido pela microturbina pode ser considerado de qualidade mais alta que o calor das células de ácido fosfórico, o qual é reaproveitado em temperaturas entre 80 e 120 ${ }^{\circ} \mathrm{C}$. Os processos de co-geração usando células a combustível de ácido fosfórico limitam-se ao aquecimento de ambientes ou de água, enquanto as microturbinas são mais eficazes no aquecimento e podem ser usadas para produção de frio; as temperaturas de exaustão das microturbinas e das células PAFC impedem a conversão de calor em eletricidade.

O balanço de planta da célula a combustível de ácido fosfórico foi analisado a partir de dados de operação e da modelagem teórica dos balanços de massa e de energia da planta. Os resultados são importantes para o desenvolvimento de plantas de energia baseadas em células a combustível, objetivo do ProH2/MCT e coerente com o Roteiro do Hidrogênio do MME. O trabalho é fruto da dissertação de mestrado de um dos autores ${ }^{24}$.

\section{Descrição da planta PC25C}

A célula a combustível modelo PC25C é composta basicamente pelas unidades de geração de hidrogênio, geração de energia elétrica, geração de vapor, refrigeração e tratamento de água.

A unidade de geração de hidrogênio é integrada à planta para evitar armazenagem de hidrogênio, que requer tecnologia de materiais avançados e/ou sistemas de alta pressão ${ }^{25}$. Três reatores compõem a unidade de geração de hidrogênio: reator de hidrodessulfurização (HDS), reator de reforma a vapor de gás natural e reator de deslocamento de água. A Figura 2 apresenta o fluxograma da unidade de geração de hidrogênio, acoplada à célula a combustível.

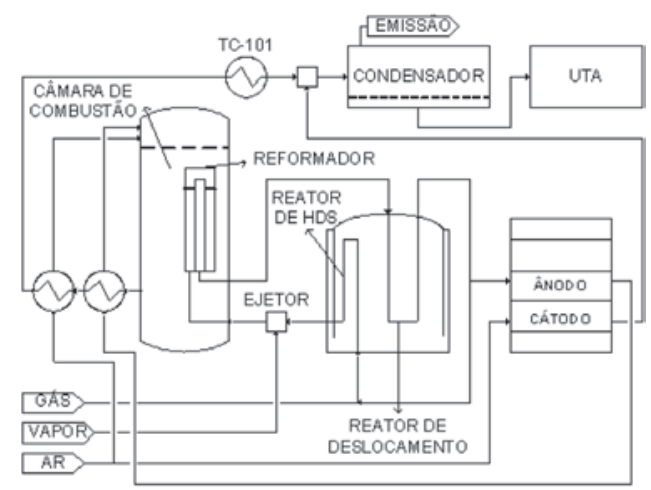

Figura 2. Fluxograma das unidades de geração de hidrogênio e de energia elétrica

A produção de hidrogênio inicia-se com a reação de hidrodessulfurização, pois o catalisador empregado no processo de reforma a vapor, em geral à base de níquel, é envenenado pelo enxofre que vem com o gás natural na forma de $\mathrm{H}_{2} \mathrm{~S}$, mercaptanas, tiofenos etc ${ }^{26}$. O gás natural tratado no reator de hidrodessulfurização é injetado em uma corrente de vapor de água, vinda da unidade de geração de vapor, para alimentar o reator de reforma. O gás de síntese gerado neste reator é encaminhado para o reator de deslocamento de água, onde o monóxido de carbono é convertido a dióxido de carbono e hidrogênio. Esta etapa evita a contaminação do catalisador de platina da célula a combustível pelo monóxido de carbono ${ }^{27}$.

A geração de energia elétrica ocorre no reator eletroquímico (pilha de células a combustível) por meio da reação de oxirredução entre o hidrogênio, contido no gás de síntese oriundo da unidade de geração de hidrogênio, e o oxigênio atmosférico. A energia elétrica gerada neste processo passa por um inversor de corrente que converte a corrente contínua, característica do processo eletroquímico, em corrente alternada própria para alimentação de cargas elétricas convencionais. A unidade de geração de eletricidade contém ainda um módulo de controle, responsável pela automação de todo o processo e usado para operação local ou remota. 
A unidade de geração do vapor consumido na reação de reforma do gás natural é composta por um tanque separador, o qual centraliza as correntes de água que trocam calor com o reator eletroquímico, o reator de deslocamento de água, o aquecedor elétrico e outros trocadores de calor. A Figura 3 apresenta o fluxograma da unidade de geração de vapor.

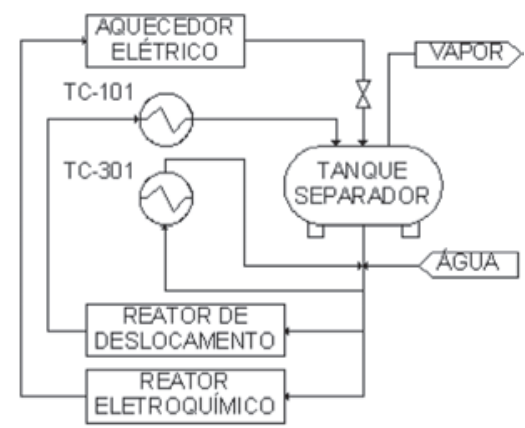

Figura 3. Fluxograma da unidade de geração de vapor

O tanque separador opera nas condições de saturação da água. A fração de água vaporizada contida dentro do tanque separador é encaminhada para a unidade de geração de hidrogênio. A fração líquida permanece em circulação e é usada nas operações associadas à geração de vapor, recuperando calor e vaporizando-se parcialmente. O líquido saturado que deixa o tanque separador misturase a uma corrente de água sub-resfriada vinda da unidade de tratamento de água e é resfriado pela passagem do fluido refrigerante, no trocador de calor TC-301 (Figura 3), para evitar que haja a vaporização parcial do líquido dentro dos equipamentos associados ao sistema de geração de vapor. A vaporização parcial do líquido ocorre na entrada do tanque separador através de uma válvula redutora de pressão. $\mathrm{O}$ aquecedor elétrico supre a demanda térmica necessária à geração de vapor, consumindo parte da energia elétrica gerada pela unidade PC25C.

$\mathrm{O}$ calor excedente da unidade $\mathrm{PC} 25 \mathrm{C}$ é removido pela unidade de refrigeração. O fluido refrigerante, uma mistura de água e propileno glicol, promove a condensação parcial do vapor de água contido no gás de exaustão e o resfriamento prévio da corrente de água utilizada para a geração de vapor no trocador de calor TC301. A entalpia adquirida pelo fluido refrigerante é destinada à cogeração ou descartada para a atmosfera, como no caso da PC25C avaliada neste estudo. A Figura 4 apresenta o fluxograma da unidade de refrigeração.

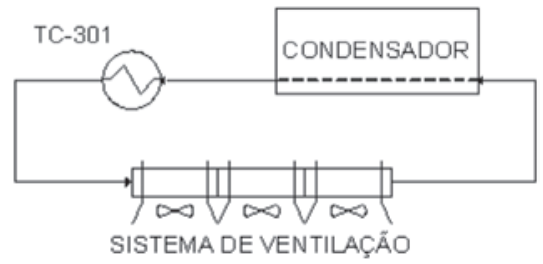

Figura 4. Fluxograma da unidade de refrigeração

O vapor condensado pela passagem do fluido refrigerante no condensador é encaminhado à unidade de tratamento de água. Depois de tratada, a água é utilizada para alimentar a unidade de geração de vapor.

\section{PARTE EXPERIMENTAL}

Os dados experimentais foram levantados em função da potência elétrica nominal, que é a potência elétrica disponível para as cargas alimentadas pela planta. Foram avaliados os seguintes parâmetros: vazão de gás natural na entrada da PC25C; vazão de fluido refrigerante; temperatura do fluido refrigerante na entrada e na saída do sistema de ventilação; diferença de potencial do reator eletroquímico, medido na pilha de células unitárias e corrente elétrica do reator eletroquímico.

As medidas foram feitas usando três sistemas de aquisição de dados (SAD): SAD I - sistema original da planta, para medição da vazão de gás natural, fluxos internos e temperaturas de operação; SAD II - medição da vazão de água no sistema externo de refrigeração e medição adicional da vazão de gás natural. Foram usados módulo transdutor Spirax-Sarco e software desenvolvido pela Marrari Automação Industrial Ltda e SAD III - medição de temperatura em pontos adicionais da planta. A temperatura foi medida nas entradas dos reatores de reforma e de deslocamento e nas saídas do ânodo e do cátodo da célula, da câmara de combustão do reformador e trocadores de calor. Foi usado um módulo transdutor da Hottinger Baldwin Messtechnik, modelo Spider 8.0, $600 \mathrm{~Hz}$.

A metodologia usada para obtenção dos dados foi: fixação da potência nominal; acompanhamento dos perfis das temperaturas para verificar quando o sistema atinge o regime estacionário; aquisição dos dados de vazão, temperatura, pressão, corrente e voltagem - os dados foram adquiridos em triplicata; determinação da vazão de vapor que alimenta o reator de reforma; alteração aleatória da potência nominal e repetição dos passos anteriores até completar toda a faixa de potência, compreendida entre zero e $200 \mathrm{~kW}$. A mudança aleatória da potência nominal foi adotada para evitar histerese.

\section{Modelagem matemática}

O modelo matemático usado neste trabalho baseia-se em equações de balanço de massa e de energia, calculadas nas diferentes unidades da planta. Considerou-se que os reatores de reforma e de deslocamento de água operam no limite termodinâmico, sendo desprezadas as limitações cinéticas e de transferência de massa interna e externa aos catalisadores dos reatores. Desta forma, a composição da corrente que alimenta o reator eletroquímico pôde ser determinada ${ }^{26}$.

O modelo aplicado parte de uma estimativa inicial para a vazão do gás natural (aproximado a 100\% de metano), calcula o balanço de massa nas unidades de geração de hidrogênio e no reator eletroquímico e o balanço energético no volume de controle (VC) do reformador, até que a diferença entre o somatório das energias de entrada e de saída no VC seja nula. A partir daí, são calculados os balanços de energia das outras operações existentes na planta e determinadas as temperaturas teóricas em diversas correntes. As temperaturas teóricas foram comparadas com as medições feitas por meio dos SAD I e III, mencionados acima.

A potência elétrica total gerada pelo reator eletroquímico é determinada através da Equação 1

$P_{E T}=I . E_{O P}$

onde: $P_{E T}=$ potência elétrica total fornecida pelo reator eletroquímico $[\mathrm{J} / \mathrm{s}] ; I=$ corrente elétrica do reator eletroquímico [A]; $E_{O P}=$ potencial de operação do reator eletroquímico [V].

Parte da eletricidade gerada no reator eletroquímico é consumida pela planta nas operações necessárias ao seu funcionamento, tais como aquecimento de água para produção de vapor, bombas, motores e válvulas. A potência elétrica consumida pode ser obtida pela diferença entre a potência elétrica gerada no reator eletroquímico, dada pela Equação 1, e a potência elétrica nominal de operação da planta fornecida no painel de controle, usando a Equação 2 
$P_{E C}=P_{E T}-P_{E N}$

onde: $P_{E C}=$ potência elétrica consumida pela PC25C $[\mathrm{J} / \mathrm{s}] ; P_{E N}=$ potência elétrica nominal $[\mathrm{J} / \mathrm{s}]$.

A potência térmica dissipada do fluido refrigerante para a atmosfera pode ser determinada pela Equação 3

$P_{T D}=m_{F R} \cdot C_{P F R} \cdot\left(T_{E}-T_{S}\right)$

onde: $P_{T D}=$ potência térmica dissipada para a atmosfera $[\mathrm{J} / \mathrm{s}] ; m_{F R}$ = vazão molar do fluido refrigerante $[\mathrm{mol} / \mathrm{s}] ; C_{P F R}=$ capacidade calorífica do fluido refrigerante a pressão constante $[\mathrm{J} / \mathrm{mol} . \mathrm{K}] ; T_{E}$ $=$ temperatura do fluido refrigerante na entrada do sistema de ventilação $[\mathrm{K}] ; T_{S}=$ temperatura do fluido refrigerante na saída do sistema de ventilação [K].

A eficiência da planta foi calculada adotando como referência o poder calorífico superior (PCS) do metano, que é a quantidade de energia liberada pela combustão completa de uma certa quantidade da substância combustível, considerando a condensação total da água contida no produto da queima. As eficiências elétrica, térmica e total da PC25C, baseadas no PCS do metano, podem ser calculadas pelas Equações 4 a 6

$\varepsilon_{E}=P_{E N} / P_{M A X}$

$\varepsilon_{T}=P_{T D} / P_{M A X}$

$\varepsilon_{\text {Total }}=\varepsilon_{E}+\varepsilon_{T}$

sendo $P_{M A X}$ a potência teórica máxima, definida pela Equação 7

$P_{M A X}=m_{C H 4} \cdot P C S_{C H 4}$

onde: $\varepsilon_{E}=$ eficiência elétrica; $\varepsilon_{T}=$ eficiência térmica; $\varepsilon_{\text {Total }}=$ eficiência total; $m_{C H 4}=$ vazão molar de gás natural que alimenta a unidade $\mathrm{PC} 25 \mathrm{C}[\mathrm{mol} / \mathrm{s}] ; \mathrm{PCS}_{\mathrm{CH} 4}=$ poder calorífico superior do metano [J/mol].

\section{RESULTADOS}

Os dados experimentais utilizados na avaliação da eficiência da unidade PC25C estão listados na Tabela 1.

Tabela 1. Dados experimentais obtidos para a planta PC25C

\begin{tabular}{lcccccc}
\hline $\begin{array}{l}\text { Potência } \\
\text { nominal }(\mathrm{kW})\end{array}$ & $\begin{array}{c}I \\
(\mathrm{~A})\end{array}$ & $\begin{array}{c}E_{O P} \\
(\mathrm{~V})\end{array}$ & $\begin{array}{c}m_{F R} \\
(\mathrm{~mol} / \mathrm{h})\end{array}$ & $\begin{array}{c}m_{C H 4} \\
(\mathrm{~mol} / \mathrm{h})\end{array}$ & $\begin{array}{c}T_{E} \\
(\mathrm{~K})\end{array}$ & $\begin{array}{c}T_{S} \\
(\mathrm{~K})\end{array}$ \\
\hline 0 & 453,0 & 193,0 & 818 & 107,0 & 355 & 298 \\
20 & 529,0 & 189,7 & 961 & 118,8 & 355 & 299 \\
40 & 661,0 & 183,9 & 1104 & 122,5 & 358 & 299 \\
60 & 645,0 & 185,6 & 1124 & 121,3 & 353 & 299 \\
80 & 689,0 & 183,4 & 1124 & 115,0 & 352 & 299 \\
100 & 727,0 & 182,3 & 1220 & 119,8 & 347 & 297 \\
120 & 830,0 & 180,0 & 1410 & 120,5 & 352 & 298 \\
140 & 930,0 & 177,0 & 1696 & 129,4 & 355 & 298 \\
160 & $1.060,0$ & 173,5 & 2003 & 148,5 & 358 & 299 \\
180 & $1.230,0$ & 169,5 & 2330 & 178,2 & 357 & 299 \\
200 & $1.413,0$ & 164,9 & 2649 & 309,3 & 346 & 309 \\
\hline
\end{tabular}

Na Tabela 2 estão os valores das potências elétricas e térmicas, obtidas pelas Equações 1, 2, 3 e 7, respectivamente, para todas as potências elétricas nominais avaliadas. A potência máxima da unidade PC25C foi calculada em relação ao poder calorífico superior do metano, que é de $890,35 \mathrm{~kJ} / \mathrm{mol}^{28}$.
Tabela 2. Potências calculadas para a unidade PC25C

\begin{tabular}{lcccc}
\hline Potência nominal $(\mathrm{kW})$ & $\begin{array}{c}P_{E T} \\
(\mathrm{~kW})\end{array}$ & $\begin{array}{c}P_{E C} \\
(\mathrm{~kW})\end{array}$ & $\begin{array}{c}P_{T D} \\
(\mathrm{~kW})\end{array}$ & $\begin{array}{c}P_{M A X} \\
(\mathrm{~kW})\end{array}$ \\
\hline 0 & 87,4 & 87,4 & 169,2 & 205,3 \\
20 & 100,4 & 80,4 & 185,8 & 239,2 \\
40 & 121,6 & 81,6 & 205,8 & 296,6 \\
60 & 119,7 & 59,7 & 183,7 & 291,0 \\
80 & 126,4 & 46,4 & 170,9 & 311,0 \\
100 & 132,5 & 32,5 & 166,4 & 325,6 \\
120 & 149,4 & 29,4 & 180,7 & 375,2 \\
140 & 164,6 & 24,6 & 204,9 & 422,5 \\
160 & 183,9 & 23,9 & 243,4 & 485,5 \\
180 & 208,5 & 28,5 & 288,4 & 565,5 \\
200 & 233,0 & 33,0 & 343,7 & 653,3 \\
\hline
\end{tabular}

A Figura 5 representa graficamente a potência elétrica consumida pela planta PC25C em função da potência elétrica nominal de operação.

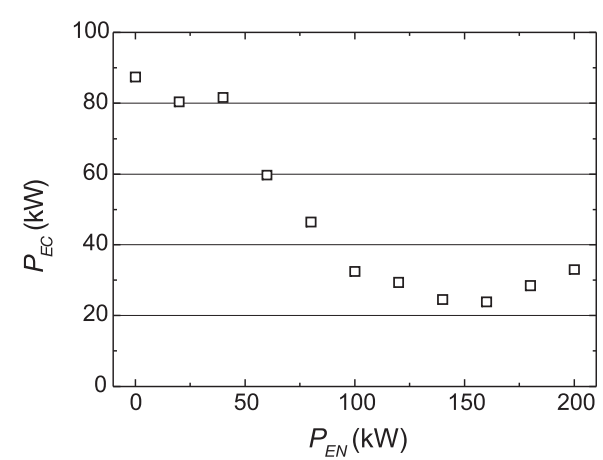

Figura 5. Potência elétrica consumida pela unidade PC25C

No intervalo de potência elétrica nominal compreendido entre 0 e $40 \mathrm{~kW}$ a planta apresenta um grande consumo de energia elétrica. Isto ocorre porque a demanda térmica da unidade de geração de vapor está sendo suprida pelo aquecedor elétrico, o qual passa a ser desligado gradativamente no intervalo de potência elétrica nominal entre 40 e $120 \mathrm{~kW}$, uma vez que nesta faixa de potência a taxa de calor liberado pelo sistema de geração de vapor torna-se maior, diminuindo a necessidade de aquecimento. $\mathrm{O}$ aquecedor elétrico é totalmente desligado a partir de $120 \mathrm{~kW}$ de potência elétrica nominal.

Para a faixa de potência nominal entre 160 e $200 \mathrm{~kW}$ o consumo de energia elétrica sofre novo aumento, devido ao aumento da rotação das bombas e ao acionamento mais freqüente do sistema de ventilação, que rejeita para a atmosfera a energia térmica remanescente do processo. O comportamento da potência elétrica consumida em função da potência elétrica nominal influencia diretamente a eficiência elétrica da planta PC25C.

$\mathrm{Na}$ Tabela 3 estão as eficiências da planta (elétrica, térmica e total), obtidas pelas Equações 4, 5 e 6, respectivamente, em função da potência nominal. Estes dados estão representados graficamente na Figura 6.

A análise da Figura 6 mostra que a eficiência total da planta se mantém praticamente constante para toda a faixa de potência elétrica nominal avaliada, em torno de $83 \%$ (PCS). As microturbinas a gás consideradas neste estudo apresentam eficiências totais inferiores a $70 \%(\mathrm{PCS})^{23}$.

A máxima eficiência elétrica da planta PC25C é de 33,1\% (PCS), para uma potência elétrica nominal de $140 \mathrm{~kW}$, enquanto que a microturbina do modelo Capstone 330 de Alta Pressão apresenta 
Tabela 3. Eficiências da unidade PC25C

\begin{tabular}{lccc}
\hline Potência nominal $(\mathrm{kW})$ & $\varepsilon_{E}(\%)$ & $\varepsilon_{T}(\%)$ & $\varepsilon_{\text {TOTAL }}(\%)$ \\
\hline 0 & 0,0 & 82,4 & 82,4 \\
20 & 8,4 & 77,6 & 86,0 \\
40 & 13,5 & 69,4 & 82,9 \\
60 & 20,6 & 63,1 & 83,7 \\
80 & 25,7 & 55,0 & 80,7 \\
100 & 30,7 & 51,1 & 81,8 \\
120 & 32,0 & 48,2 & 80,2 \\
140 & 33,1 & 48,5 & 81,6 \\
160 & 33,0 & 50,1 & 83,1 \\
180 & 31,8 & 51,0 & 82,8 \\
200 & 30,6 & 52,6 & 83,2 \\
\hline
\end{tabular}

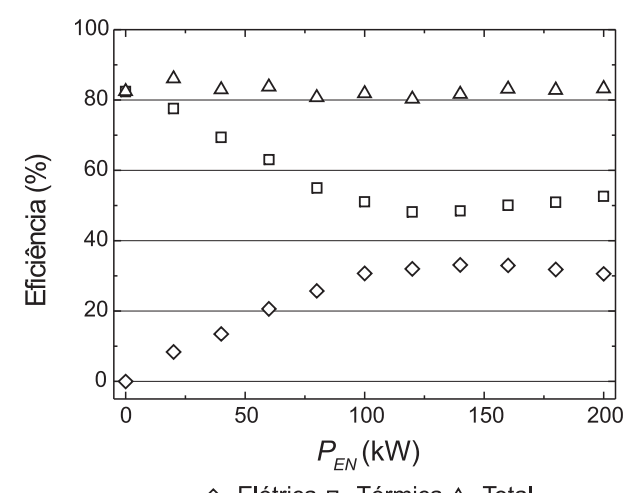

Figura 6. Eficiências da planta PC25C, baseadas no PCS do metano

uma eficiência elétrica máxima de $24,5 \%$ (PCS) ${ }^{23}$. Este modelo de microturbina apresenta a maior eficiência elétrica dentre as microturbinas do mesmo fornecedor. Para potências elétricas nominais menores que $80 \mathrm{~kW}$, a planta PC25C apresenta eficiência elétrica inferior às apresentadas pelas microturbinas da Capstone.

À medida que a potência elétrica nominal da célula é elevada, no intervalo compreendido entre 0 e $140 \mathrm{~kW}$, observa-se um aumento na eficiência elétrica da unidade. A partir deste ponto, ocorre a inversão desta tendência. Este comportamento pode ser explicado com base na potência elétrica consumida pela planta, conforme explicado anteriormente.

A eficiência térmica da planta também é superior à eficiência térmica da microturbina considerada: enquanto o valor mínimo de $\varepsilon_{T}$ para a PC25C é de $48,2 \%$ (Tabela 3 ) a eficiência térmica da Capstone 330 é $44,8 \%{ }^{23}$, embora a qualidade do calor da microturbina seja superior e tenha mais aplicações.

Para uma potência elétrica nominal de $0 \mathrm{~kW}$, condição conhecida como modo de espera, toda a energia elétrica gerada pelo reator eletroquímico é convertida em energia térmica, visando manter o aquecimento global das operações da unidade. Nesta condição, a eficiência térmica da planta é máxima. A princípio pode parecer vantajoso aumentar a vazão do fluido refrigerante para obter maior eficiência térmica. Porém, isto implica em um aumento no consumo de energia elétrica por parte do sistema de ventilação, do sistema de bombeamento e do aquecedor elétrico. O aumento da vazão do fluido refrigerante no trocador de calor TC-301 provoca demasiado resfriamento da água que circula pelo sistema de geração de vapor e, como consequiência, a energia elétrica consumida pelo aquecedor AE-301 aumenta. A soma destes fatores diminui a eficiência elétrica da unidade PC25C. Além disto, o aumento da vazão do fluido refrigerante faz com que o sistema de refrigeração opere em níveis mais baixos de temperatura, impossibilitando a utilização da energia térmica.

\section{Avaliação do reator eletroquímico}

A modelagem aplicada a todas as correntes permite avaliar a tecnologia de células a combustível de ácido fosfórico, utilizada na planta PC25C. É possível calcular a eficiência elétrica da pilha de células a combustível a partir dos dados experimentais de potência total, obtida pela multiplicação da tensão pela corrente medidas na célula, e dos valores teóricos de vazão de hidrogênio na entrada e na saída da célula.

A Tabela 4 mostra os valores experimentais da potência total e os valores teóricos da vazão molar de hidrogênio consumido pela célula. A eficiência da célula a combustível foi calculada a partir da razão entre a potência total produzida e o poder calorífico superior do hidrogênio consumido pela célula a combustível. As curvas de tensão e potência em função da corrente são mostradas na Figura 7, enquanto a Figura 8 mostra a variação da eficiência da célula com a potência nominal da planta.

Tabela 4. Potência total, vazões molares e eficiência na unidade de conversão eletroquímica

\begin{tabular}{lccccc}
\hline $\begin{array}{l}\text { Potência } \\
\text { nominal }(\mathrm{kW})\end{array}$ & $\begin{array}{c}\text { Tensão } \\
(\mathrm{V})\end{array}$ & $\begin{array}{c}\text { Corrente } \\
(\mathrm{A})\end{array}$ & $\begin{array}{c}\text { Potência } \\
\text { total }(\mathrm{kW})\end{array}$ & $\begin{array}{c}\mathrm{H}_{2} \text { usado } \\
(\mathrm{mol} / \mathrm{h})\end{array}$ & $\begin{array}{c}\text { Eficiência } \\
\text { da CaC }(\%)\end{array}$ \\
\hline 0 & 193,0 & 453,0 & 87,4 & $2.366,0$ & $46,8 \%$ \\
20 & 189,7 & 529,0 & 100,4 & $2.762,8$ & $46,0 \%$ \\
40 & 183,9 & 661,0 & 121,6 & $3.452,2$ & $44,6 \%$ \\
60 & 185,6 & 645,0 & 119,7 & $3.368,7$ & $45,0 \%$ \\
80 & 183,4 & 689,0 & 126,4 & $3.598,5$ & $44,5 \%$ \\
100 & 182,3 & 727,0 & 132,5 & $3.797,0$ & $44,2 \%$ \\
120 & 180,0 & 830,0 & 149,4 & $4.335,0$ & $43,7 \%$ \\
140 & 177,0 & 930,0 & 164,6 & $4.857,2$ & $43,0 \%$ \\
160 & 173,5 & $1.060,0$ & 183,9 & $5.536,1$ & $42,1 \%$ \\
180 & 169,5 & $1.230,0$ & 208,5 & $6.424,0$ & $41,1 \%$ \\
200 & 164,9 & $1.413,0$ & 233,0 & $7.379,8$ & $40,0 \%$ \\
\hline
\end{tabular}

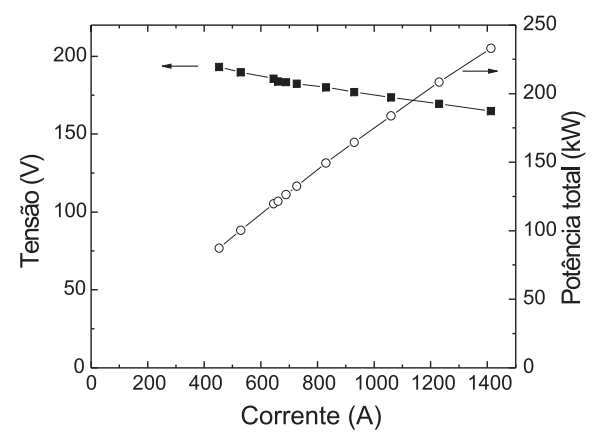

Figura 7. Curvas de tensão e potência elétrica versus corrente, medidas na célula

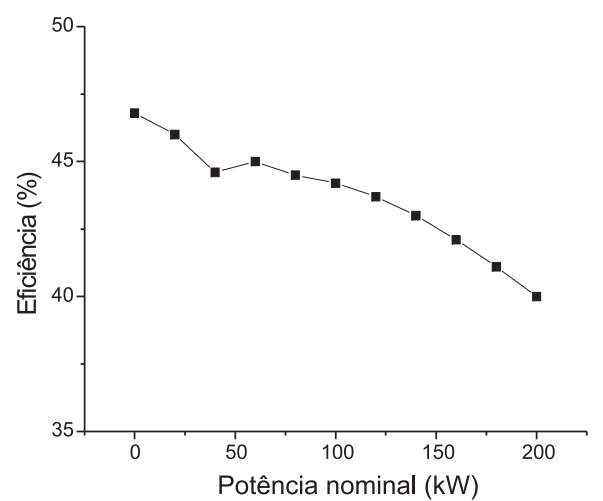

Figura 8. Eficiência elétrica da célula a combustível, em relação ao PCS (H2) 
O comportamento da potência e da tensão elétrica em função da corrente é coerente com os dados obtidos da literatura para células PAFC de $50 \mathrm{~kW}^{14}$ e seguem o padrão esperado para células a combustível em geral $^{25,27}$. A eficiência elétrica mostrada na Figura 8 reflete o desempenho da unidade de conversão eletroquímica isolado, e por isso é diferente do comportamento mostrado na Figura 6, obtido para a planta como um todo. A comparação destes dados indica o comportamento elétrico da planta PC25C.

$\mathrm{Na}$ faixa de potência nominal entre 20 e $200 \mathrm{~kW}$ o reator eletroquímico apresenta eficiência variando entre 46 e 40\%. Para a potência nominal de $140 \mathrm{~kW}$ (máxima eficiência elétrica da planta) a célula possui eficiência elétrica de $43 \%$ contra $33,1 \%$ da planta, o que significa uma perda de $23 \%$ da potência elétrica disponível no reator eletroquímico, devido ao consumo nas operações da planta, tais como aquecimento e circulação de fluidos.

\section{CONCLUSÃO}

A eficiência elétrica da planta $\mathrm{PC} 25 \mathrm{C}$ varia com a potência nominal, sendo a máxima eficiência elétrica $(33,1 \%)$ observada para a potência elétrica nominal de $140 \mathrm{~kW}$, tendo como referência o poder calorífico superior do metano. Nesta condição, a planta é cerca de $35 \%$ mais eficiente que a microturbina a gás do modelo Capstone 330 de alta pressão; as eficiências térmica e total da unidade PC25C também se mostraram superiores às apresentadas pela microturbinas a gás. Como conseqüência, a célula a combustível emite menos poluentes para uma mesma potência elétrica nominal de operação. Porém, para potências elétricas nominais inferiores a $80 \mathrm{~kW}$, a unidade PC25C é menos eficiente que a mesma microturbina, bem como a qualidade do calor recuperável é inferior para a PAFC.

A unidade de conversão eletroquímica (célula a combustível) da planta PC25C também foi avaliada. Verificou-se que a eficiência de conversão do hidrogênio em eletricidade cai com a potência elétrica nominal, o que é esperado para as células a combustível em geral. As curvas de tensão e de potência elétrica em função da corrente também são coerentes com os dados para células PAFC de outras potências.

Os resultados apresentados indicam que o desenvolvimento de sistemas de células a combustível depende da sinergia entre a célula a combustível e as unidades de geração de hidrogênio e de vapor, de refrigeração e de tratamento de água. O projeto de uma planta baseada em células a combustível de qualquer tipo precisa atingir o melhor equilíbrio entre todas as operações da planta, sendo a conversão eletroquímica apenas uma delas.

Finalmente, pode-se concluir que células a combustível de ácido fosfórico são adequadas à geração estacionária de energia devido às suas características de durabilidade e eficiência energética. A possibilidade de redução de custo de fabricação de plantas baseadas em células de ácido fosfórico requer o avanço na compreensão dos sistemas de células a combustível PAFC e os resultados aqui apresentados contribuem para este avanço.

\section{AGRADECIMENTOS}

À COPEL Geração S/A pelo financiamento deste trabalho, com recursos do Programa ANEEL de P\&D. M. P. Cantão agradece ao Eng. M. C. do Nascimento, da COPEL/DGC/CDT, pela gerência do projeto onde foram desenvolvidas as atividades da equipe.

\section{REFERÊNCIAS}

1. Spinacé, E. V.; Oliveira Neto, A.; Franco, E. G.; Linardi, M.; Gonzalez, E. R.; Quim. Nova 2004, 27, 648.

2. Wendt, H.; Linardi, M.; Aricó, E. M.; Quim. Nova 2002, 25, 470.

3. Wendt, H.; Götz, M.; Linardi, M.; Quim. Nova 2000, 23, 538.

4. Gonzalez, E. R.; Quim. Nova 2000, 23, 262.

5. Cantão, M. P.; $2^{\circ}$ Workshop de Células a Combustível, Campinas, Brasil, 2004.

6. www.mct.gov.br, acessada em Junho 2006.

7. www.mme.gov.br, acessada em Junho 2006.

8. Caires, M. I.; Buzzo, M. L.; Ticianelli, E. A.; Gonzalez, E. R.; J. Appl. Electrochem. 1997, 27, 19.

9. de Sena, D. R.; Gonzalez, E. R.; Ticianelli, E. A.; Electrochim. Acta 1992, 37,1855 .

10. Choudhury, S. R.; Rengaswamy, R.; J. Power Sources 2006, 161, 971.

11. Bizarri, G.; Appl. Therm. Eng. 2006, 26, 1001.

12. Choudhury, Sum. R.; Choudhury, Suh. R.; Rangarajan, J.; Rengaswamy R.; J. Power Sources 2005, 140, 274.

13. Sammes, N.; Bove, R.; Stahl, K.; Curr. Opin. Solid State Mater. Sci. 2004, $8,372$.

14. Yang, J. C.; Park, Y. S.; Seo, S. H.; Lee, H. J.; Noh, J. S.; J. Power Sources 2002, 106, 68.

15. Zervas, P. L.; Koukou, M. K.; Markatos, N. C.; Energy Conversion Manage. 2006, 47, 2883.

16. Choudhury, S. R.; Deshmukh, M. B.; Rengaswamy, R.; J. Power Sources 2002, 112, 137.

17. Dheenadayalan, S.; Song, R.-H.; Shin, D.-R.; J. Power Sources 2002, 107, 98.

18. McIlveen-Wright, D.; Guiney, D. J.; J. Power Sources 2002, 106, 93.

19. Machado, N. R. C. F.; Nascimento, M. C.; Cantão, M. P.; Rizzo, R. P. C.; Alonso, C. G.; Bessani, A. N.; Cavenaghi, A. D.; Wauke, F. T.; Freitas, N. M.; Anais do XVIII Seminário Nacional de Produção e Transmissão de Energia Elétrica - XVIIIX SNPTEE, Curitiba, Brasil, 2005.

20. Santos, R. K. S.; Batista, M. S.; Assaf, E. M.; Assaf, J. M.; Quim. Nova 2005, 28, 587.

21. Noronha, F. B.; Mattos, L. V.; J. Power Sources 2005, 152, 50.

22. Mattos, L. V.; Noronha, F. B.; J. Power Sources 2005, 145, 10.

23. www.microturbine.com, acessada em Fevereiro 2006.

24. Camparin, R. H.; Dissertação de Mestrado, Universidade Federal do Paraná, Brasil, 2006.

25. Larminie, J.; Dicks, A.; Fuel Cell Systems Explained, $2^{\text {nd }}$ ed., John Wiley \& Sons: West Sussex, 2003.

26. Yamamoto, C. I.; Dissertação de Mestrado, Universidade de São Paulo, Brasil, 1990.

27. EG\&G Technical Services, Inc.; Fuel Cell Handbook, $7^{\text {th }}$ ed., USDOE: Morgantown, WV, 2004.

28. Sandler, S. I.; Chemical and Engineering Thermodynamics, $3^{\text {rd }}$ ed., John Wiley \& Sons: New York, 1999. 